\title{
Report of an unusually Huge Fibroepithelial Polyp managed with Diode Laser
}

\author{
${ }^{1}$ Shashwati Paul, ${ }^{2}$ Anuroopa Pudukulangara, ${ }^{3}$ Rithesh Kulal, ${ }^{4}$ Savita Sambashivaiah
}

\begin{abstract}
Fibromas are benign tumors that are composed of fibrous connective tissue. Fibroepithelial polyp (FEP) is a histological variant of fibroma that causes esthetic and functional problems. They may arise anywhere in the oral cavity, but are more commonly seen in the gingiva, tongue, and lip. Generally small and painless, they rarely continue to grow and might resemble other malignant lesions. This article reports an unusual case of a huge intraoral FEP that presented as a cauliflower-shaped lesion mimicking other neoplastic lesions. Laser excision was carried out following which histopathological examination revealed it as an inflamed FEP with ulceration.
\end{abstract}

Keywords: Fibroepithelial polyp, Fibroma, Histopathology, Laser, Malignancy, Neoplastic lesion.

How to cite this article: Paul S, Pudukulangara A, Kulal R, Sambashivaiah S. Report of an unusually Huge Fibroepithelial Polyp managed with Diode Laser. J Health Sci Res 2015;6(2):52-55.

Source of support: Nil

Conflict of interest: None

\section{INTRODUCTION}

Intraoral fibrous overgrowths are common, and these could vary from irritable, developmental, and inflammatory to neoplastic lesions. These lesions can be either generalized or restricted to the site. Reactive lesions of the gingiva are clinically and histologically non-neoplastic nodular swellings that develop in response to chronic and recurrent tissue injury, which stimulates an exuberant or excessive tissue response. Fibroma of the oral mucosa is the most common benign "tumor," also known by the name of irritation fibroma (IF)/traumatic fibroma/ focal fibrous hyperplasia /fibrous nodule/fibroepithelial polyp (FEP). The occurrence of IFs among the South Indian population was found to be $39.1 \%{ }^{1}$ The lesion presents as a painless, sessile, or occasionally pedunculated swelling that can be firm and resilient or soft and spongy in consistency.

\footnotetext{
${ }^{1}$ Postgraduate Student, ${ }^{2,3}$ Reader, ${ }^{4}$ Professor and Head

${ }^{1-4}$ Department of Periodontology, RajaRajeswari Dental College and Hospital, Bengaluru, Karnataka, India
}

Corresponding Author: Shashwati Paul, Postgraduate Student, Department of Periodontology, RajaRajeswari Dental College and Hospital, Bengaluru, Karnataka, India, Phone: +918951502864, e-mail: hishashwati@gmail.com
Cooke ${ }^{2}$ described all the pedunculated swellings arising from a mucosal surface as "polyp" + (FEP), where the maximum number of lesions occurred on the mucosa in the line of occlusion. Fibroepithelial polyps are usually solitary, and reports of multiple, bilateral polyps are extremely rare. These polyps clinically appear as firm, pink, painless, sessile or pedunculated, polypoid swellings with varying sizes that range to a few millimeters. ${ }^{3}$

The etiology of these polyps is not clear. It may be caused by chronic irritation, infection, hormonal imbalance, allergic factors, minor trauma, or some developmental defects. Fibroepithelial polyps are painless but are subjected to trauma, so chance of infection prevails. They are usually pink in color unless irritated or infected. If infected, they may appear red in color.

Though these lesions are harmless and only cause functional problems, they mimic fibromas or papillomas or other neoplastic lesions in appearance. Hence, surgical excision and histological examination is a must to rule out such lesions. In this article, we present one rare case of a highly vascularized huge FEP that mimicked a neoplastic fibroma in nature and appearance.

\section{CASE REPORT}

A 21-year-old male presented to the Department of Periodontology with a chief complaint of swelling since 3 months in the right lower back teeth region. Patient gave a history of the swelling that was initially the size of a peanut, which gradually increased in size over 3 months. The growth was painless but bled during mastication and brushing. It was large, sessile, cauliflower-shaped, and lobulated with well-defined margins. On examination, it was found that the lesion originated from the attached gingiva of tooth number 46 and had two lobules, each measuring about $2 \times 1 \mathrm{~cm}$ (Fig. 1). It was pale pink in color with the surface appearing white and soft in consistency on palpation. Root stumps were present with respect to tooth number 46 . There was no history of contributory medical issues and any deleterious habits. Radiological evaluation revealed no bony changes and the patient's blood picture was within normal limit (Fig. 2). Initial phase I treatment included thorough scaling and root planing. The lesion was excised using a diode laser of wavelength $970 \mathrm{~nm}$ and $5.5 \mathrm{~W}\left(\right.$ Sirona $\left.{ }^{\circledR}\right)$, and the root 


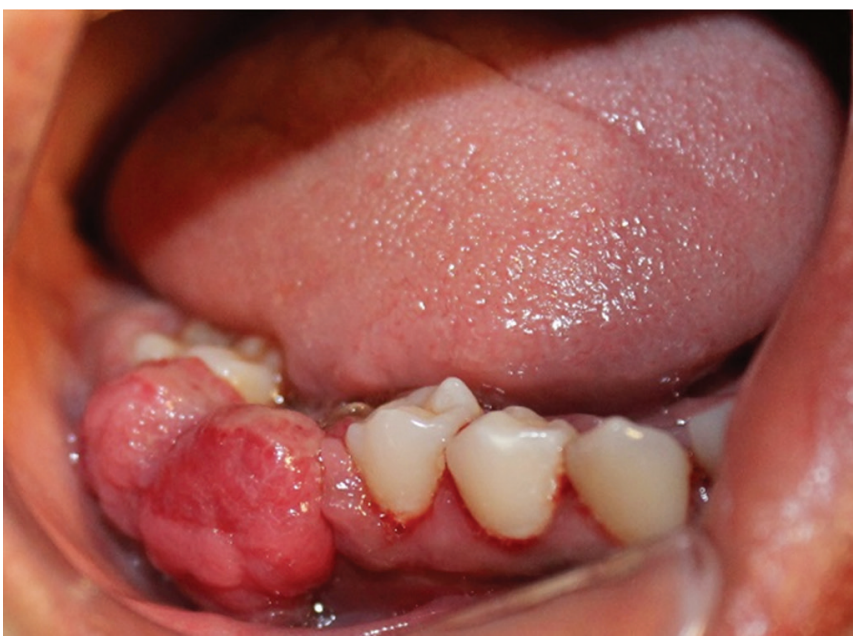

Fig. 1: Intraoral view of growth

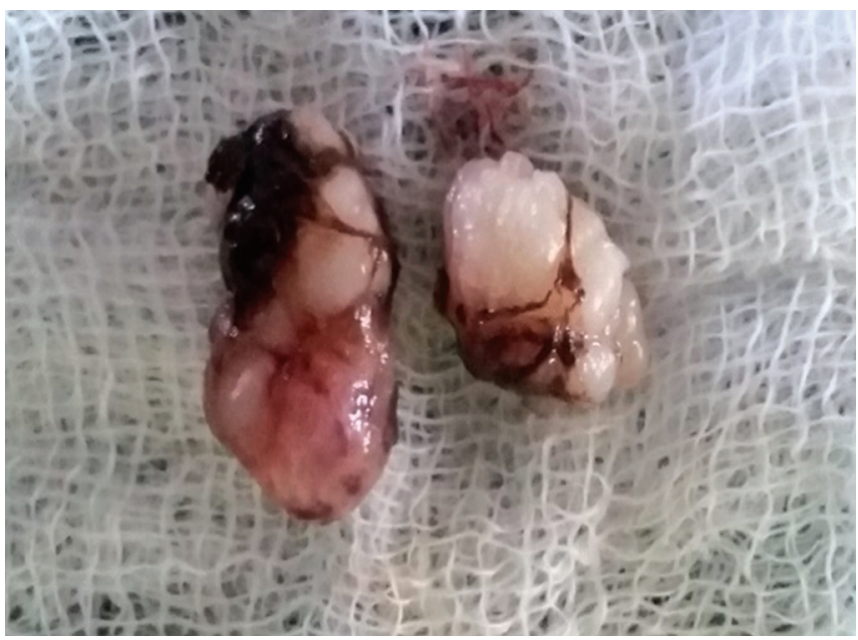

Fig. 3: Excised polyp tissue

stumps were extracted on the same day (Fig. 3). Though the lesion did not appear vascularized, profuse bleeding from the larger vessel was encountered during its excision, and this was subsequently controlled by means of suture. The patient was advised to take antibiotics and analgesics immediately after the procedure and for the next 3 days. Postoperative examination was done after a week (Fig. 4). The surgical site exhibited normal healing with no adverse reaction. At the 6 months' postoperative evaluation, the surgical site exhibited normal anatomy with no inadvertent reaction.

\section{HISTOPATHOLOGICAL EVALUATION}

Histopathological examination was done under a light microscope $(40 \times)$. Histopathological evaluation revealed connective tissue lined by stratified squamous epithelium exhibiting areas of ulceration (Fig. 5). Subepithelium showed dense mixed inflammatory cell infiltrate rich in plasma cells along with proliferating blood vessels, suggesting an inflamed FEP with ulceration. The sections were negative for granuloma or malignancy.

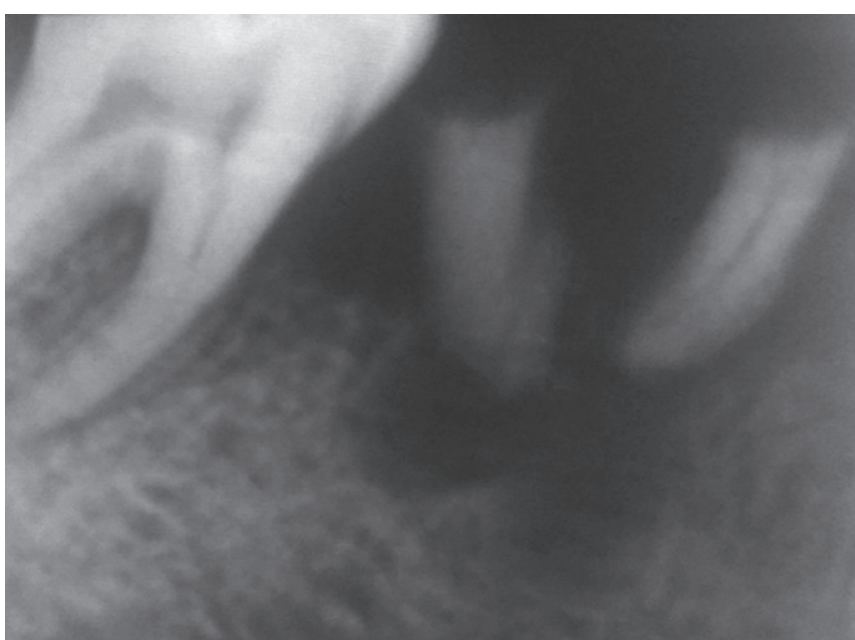

Fig. 2: Radiograph showing root stumps with respect to tooth number 46 and no other bony pathology

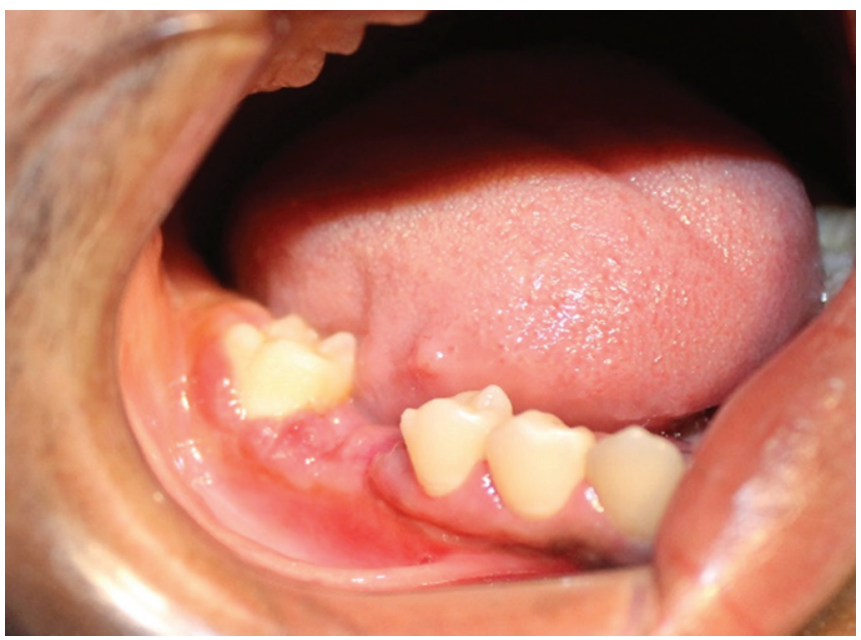

Fig. 4: One week postoperative view

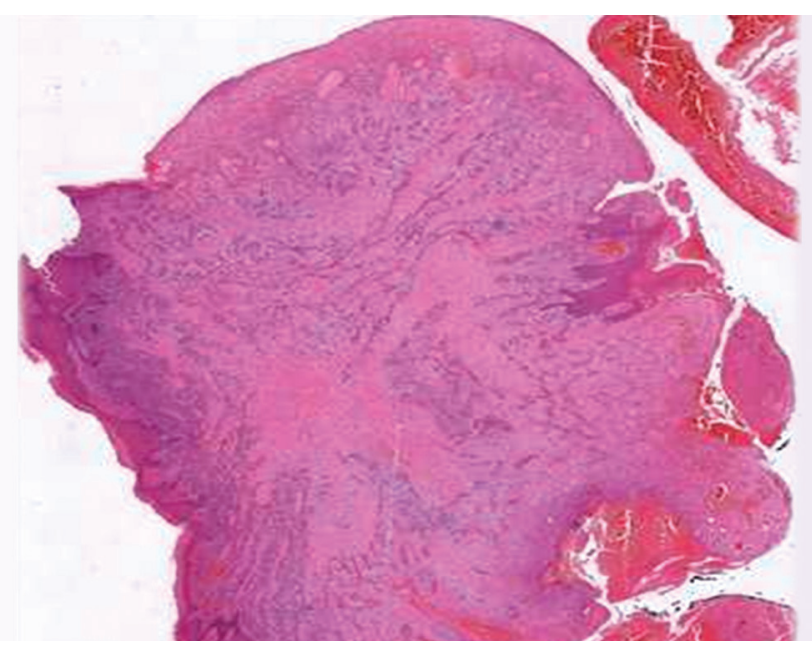

Fig. 5: Histopathological view under 40× light microscopy

\section{DISCUSSION}

Fibroepithelial polyp is a common benign lesion of mesodermal origin with extremely low incidence of malignant potential. They merely represent a reactive hyperplasia of fibrous connective tissue in response to 
trauma or irritation. ${ }^{4}$ It results in a chronic repair process that includes granulation tissue and scar formation, resulting in a fibrous submucosal mass. The trauma might be caused by irritants, such as calculi, overhanging margins, restorations, foreign bodies, chronic biting, margins of caries, and sharp spicules of bones and overextended borders of appliances. ${ }^{4}$

In a report by Arya et $\mathrm{al}^{4}{ }^{4}$ a solitary case of FEP was found in the alveolar ridge in relation to teeth numbering 46 and 47, which were clinically missing. A sharp cusp was present with respect to 17 , which was thought to be the probable irritant. In our case, there was a source of chronic irritation, which were the root stumps in relation to tooth number 46 .

These lesions are prevalent in various age groups. The peak was in the 31 to 40 years age group $(10.54 \%)$ followed by the 51 to 60 years age group (7.82\%). ${ }^{5}$ It is more common in females (29\%) compared with males $(15 \%)$. Cooke $^{2}$ observed that the greatest number of cases of fibrous hyperplasia was in the 4 th decade, while Kfir et al found the majority of cases mainly in the 2nd, 3rd, and 4th decade. The affected male was in his 2 nd decade.

The gradual increase in size of this FEP and its resemblance to a cauliflower-like growth presented as a diagnostic dilemma, which was confirmed only after histopathological evaluation. Fibroepithelial polyps occur more frequently in buccal mucosa, labial mucosa, and tongue. Clinically, they appear as broad-based lesions, lighter in color than the surrounding normal tissue, with the surface often appearing white because of hyperkeratosis or with surface ulceration caused by secondary trauma. The growth potential of fibroma does not exceed 10 to $20 \mathrm{~mm}$ in diameter. ${ }^{4}$

The clinical features of FEP are not unique. So it is very necessary to differentiate these lesions from the peripheral ossifying fibroma, pyogenic granuloma, or peripheral giant cell granuloma. Both FEP and peripheral ossifying fibroma appear pale, firm, and nontender. However, peripheral ossifying fibroma appears exclusively on the gingiva, and they may be firmer to palpate because of calcified material in the stroma. ${ }^{6,7}$ In addition, they have the tendency to displace the adjacent teeth. The pyogenic granuloma and peripheral giant cell granuloma generally appear more vascular than a fibromatous growth and may bleed when palpated or probed. In the present case, profuse bleeding was encountered during its excision, which further necessitated a histopathological examination. Lipoma might also be considered as a differential diagnosis in this case, although it is rarely seen in the oral cavity. Further, its pale yellow color and slippage on palpation excludes it from inclusion in this particular case. ${ }^{8}$
Fibroepithelial polyp must be differentiated from papillomas, which are considered to be benign neoplasm. Papillomas are composed of squamous epithelial cells that exhibit marked acanthosis, hyperkeratosis, and a papillary growth pattern, whereas FEP consists of an unremarkable fibrous stroma covered by a nonpapillary layer of hyperplastic squamous epithelium.

Fibroepithelial polyp does not pose a risk for malignancy. Recurrences rates are less and are mostly caused by repetitive trauma at the same site or failure to completely eliminate the traumatic factor. It can be treated by conservative surgical excision. In this rare case of a large highly vascularized polyp, a diode laser was used for its excision. It is a feasible substitute to the scalpel owing to its advantages that include a decline in the number of relapses in comparison with the scalpel. ${ }^{9}$ Other advantages of the laser when compared with scalpel are a highly decontaminated surgical bed, reduced mechanical trauma, and the appearance of fewer myofibroblasts resulting in comparatively lesser wound contraction. .0,11 $^{1}$ Significant benefits of using diode laser are negligible postoperative inflammation, enhanced healing, and reduced postoperative pain. ${ }^{12}$ Also, it is a less invasive method that gives a bloodless field during surgery. In the present case, bleeding was encountered during the excision of the lesion. Isolation of the area showed there was spurting of blood from a larger vessel. Lasers are able to coagulate blood vessels when used in continuous mode. But we used a pulsed mode that failed to do the same..$^{13}$ Also, lasers are unable to coagulate vessels larger than $1 \mathrm{~mm}^{14}$

\section{CONCLUSION}

Reactive lesions in oral cavity often present with very similar clinical features that can often create a difficult diagnostic situation for dentists. These lesions because of their large size pose difficulty to the patient while chewing, brushing, etc. Also, in some cases, the location of the lesion causes an unesthetic appearance. Most of all, the lesion has to be differentiated from other similar neoplastic lesions. Thus, after its complete excision and after the source of infection is removed, histopathological examination is mandatory to rule out any other pathologies. So proper management, a histopathological analysis, and regular follow-up visits comprise a complete treatment of such oral lesions.

\section{REFERENCES}

1. Shamim T, Varghese VI, Shameena PM, Sudha S. A retrospective analysis of gingival biopsied lesions in South Indian population: 2001-2006. Med Oral Patol Oral Cir Bucal 2008 Jul 1;13(7):E414-E418.

2. Cooke BE. The fibrous epulis \& the fibro epithelial polyp: their histogenesis \& natural history. Br Dent J 1952;93:305-309. 
3. Lee KW. The fibrous epulis and related lesions. Granuloma pyogenicum. Pregnancy tumor, fibroepithelial polyp and calcifying fibroblastic granuloma. A clinicopathological study. Periodontics 1968 Dec;6(6):277-292.

4. Arya S, Singhal P, Vengal M, Patil N, Bhateja S. Fibroepithelial polyp - report of two cases with literature review. IJSS Case Rep Rev 2015 Feb;1(9):9-12.

5. Bataineh A, Al-Dwairi ZN. A survey of localized lesions of oral tissues: a clinicopathological study. J Contemp Dent Pract 2005 Aug 15;6(3):30-39.

6. Neville, BW.; Damm, DD.; Allen, CM.; Bouquot, JE. Oral and maxillofacial pathology. 2nd ed. Philadelphia: Saunders; 2002.

7. Coleman, GC.; Nelson, JF. Principles of oral diagnosis. St Louis: Mosby; 1993.

8. Laller S, Saini RS, Malik M, Jain R. An appraisal of oral mucous extravasation cyst case-mini review. J Adv Med Dent Sci Res 2014 Apr-Jun;2(2):166-170.

9. Koppolu P, Mishra A, Kalakonda B, Swapna LA, Bagalkotkar A, Macha D. Fibroepithelial polyp excision with laser and scalpel: a comparative evaluation. Int J Curr Microbiol App Sci 2014 Aug;3(8):1057-1062.

10. Fisher SE, Frame JW. The effects of the carbon dioxide surgical laser on oral tissues. Br J Oral Maxillofac Surg 1984 Dec;22(6):414-425.

11. Bornstein MM, Winzap-Kälin C, Cochran DL, Buser D. The $\mathrm{CO}_{2}$ laser for excisional biopsies of oral lesions: a case series study. Int J Periodontics Restorative Dent 2005 Jun;25(3): 221-229.

12. Strauss RA. Lasers in oral and maxillofacial surgery. Dent Clin North Am 2000 Oct;44(4):851-873.

13. Borchers R. Comparison of diode lasers in soft-tissue surgery using CW- and superpulsed mode: an in vivo study. [thesis]. Aachen, Germany: RWTH Aachen University;2008. p. 1-77.

14. Ryan RW, Wolf T, Spetzler RF, Coons SW, Fink Y, Preul MC. Application of a flexible $\mathrm{CO}_{2}$ laser fiber for neurosurgery: Laser-tissue interactions. J Neurosurg 2010 Feb;112(2): 434-443. 